$9-1-2020$

\title{
Documenting lessons from an integrated social and behavior change program linked to integrated health services in Zambia
}

Breakthrough RESEARCH

Follow this and additional works at: https://knowledgecommons.popcouncil.org/departments_sbsr-rh

Part of the Health Communication Commons, and the Public Health Commons

How does access to this work benefit you? Let us know!

\section{Recommended Citation}

Breakthrough RESEARCH. 2020. "Documenting lessons from an integrated social and behavior change program linked to integrated health services in Zambia," Programmatic Research Brief. Washington, DC: Population Council. 


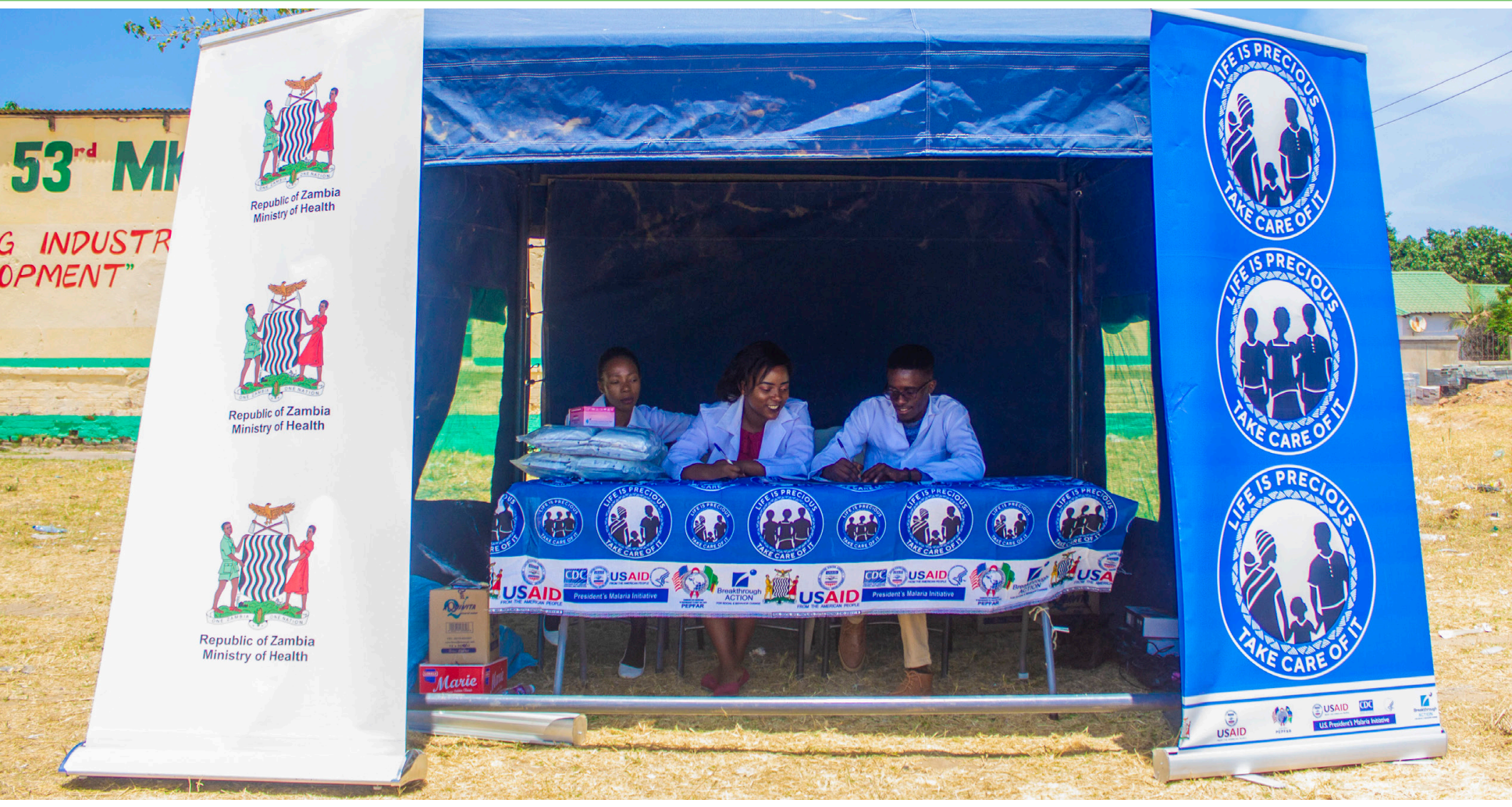

\section{Documenting Lessons from an Integrated Social and Behavior Change Program Linked to Integrated Health Services in Zambia}

This program brief documents lessons for SBC programmers implementing multi-health, community-based SBC programming with integrated health services. An iterative process by Breakthrough ACTION Zambia, from October 2018 through March 2019, identified four design concepts with strong feasibility and potential for impact and scalability. This design process included a co-design workshop, iterative testing, validation, and finalization of each design concept. These four concepts were further refined in Breakthrough ACTION Zambia provinces and districts in collaboration with implementing partners (IPs) and the Ministry of Health (MoH) Department of Health Promotion, with the final intervention designs and implementation processes determined in close collaboration with $\mathrm{MoH}$.

\footnotetext{
Men and Adolescent Wellness Days was one design concept developed to address these findings from the formative research and literature review, to promote health service uptake. Men and adolescents, as shown in Table 1 (next page), were not utilizing services and commodities such as HIV testing and family planning (FP) that are available at health facilities.
} 
TABLE 1 BEHAVIORAL INSIGHTS FROM FORMATIVE RESEARCH AND LITERATURE REVIEWa

- Men do not access condoms or HIV testing at health facilities due to concerns about privacy and confidentiality.

- Men do not discuss condom use with their partners due to fears that these conversations could imply infidelity.

- Men choose not to use condoms in the moment because of reduction in pleasure.

- Men prioritize their children's or family's use of an insecticide treated net (ITN) over their own because they believe they are at lower risk of malaria.

- Men value the health of their families but view their role as providing financial security rather involvement in health care decisions.
- Adolescents do not seek FP or condoms from health centers due to concerns about privacy and confidentiality.

- Adolescent girls do not use FP because social norms dictate that it is unacceptable for unmarried females to use FP.

- Adolescent girls do not use modern contraceptives other than condoms due to fear of side effects.

- Adolescent girls have misconceptions about FP; they believe many methods can cause infertility.

- Adolescents do not use ITNs because they or their family members perceive adolescents to be at lower risk of malaria.

- Adolescent girls have unprotected sex in transactional relationships (for money, food, or gifts) because they are unable to negotiate condom use in such relationships.

${ }^{a}$ Central Statistical Office, Zambia, Ministry of Health, ICF International. 2014. Zambia Demographic and Health Survey 2013-14. Rockville, Maryland, USA

Wellness Days were conducted once a month at selected health centers in Breakthrough ACTION Zambia and IP districts, with exact days and venues determined by the health facilities. Men 20 to 55 years of age, and male and female adolescents ages 15 to 19, were invited to health facilities for integrated preventative health services including HIV testing and condom provision, in addition to receiving information about ITN use, FP, and nutrition. Health provider counseling at Wellness Days addressed client knowledge, perceptions, practices, and norms revealed in the formative research and literature review.

Prior to Wellness Day implementation, Breakthrough ACTION Zambia trained staff from IPs and district health offices, who subsequently trained service providers of various cadres (e.g., clinical officers, registered nurses, nutritionists, environmental health technicians) from health facilities, along with community-based volunteers (CBVs), necessary for implementing Wellness Days, as shown in Figure 1. These two-day trainings involved

\section{FIGURE 1 BREAKTHROUGH ACTION ZAMBIA CASCADED TRAINING}

\section{National Training of Trainers}

Breakthrough ACTION staff at national, provincial, and district levels Implementing partners (i.e., SFH, ECR, ZCCP)

$\mathrm{MoH}$ (i.e., health promotion officers at national, provincial, and district levels

\section{District Trainings}

District Health Promotion Coordinating Committee (e.g., Government departments such as District Health Offices, District Education Boards Secretaries), local authority, civil society, Zambia News and Information Services, community radio, religious groups, etc.

\section{6+ Health Facility/Community-based Volunteer Trainings}

Health facility staff (e.g., nurse, clinical officer, lab technician, pharmacists, environmental health technologist, maternal and child health nurse) and community-based volunteers (e.g., neighborhood health committees members, traditional birth attendants, community health workers) 
FIGURE 2 HEALTH AND FITNESS INFORMATION GUIDE

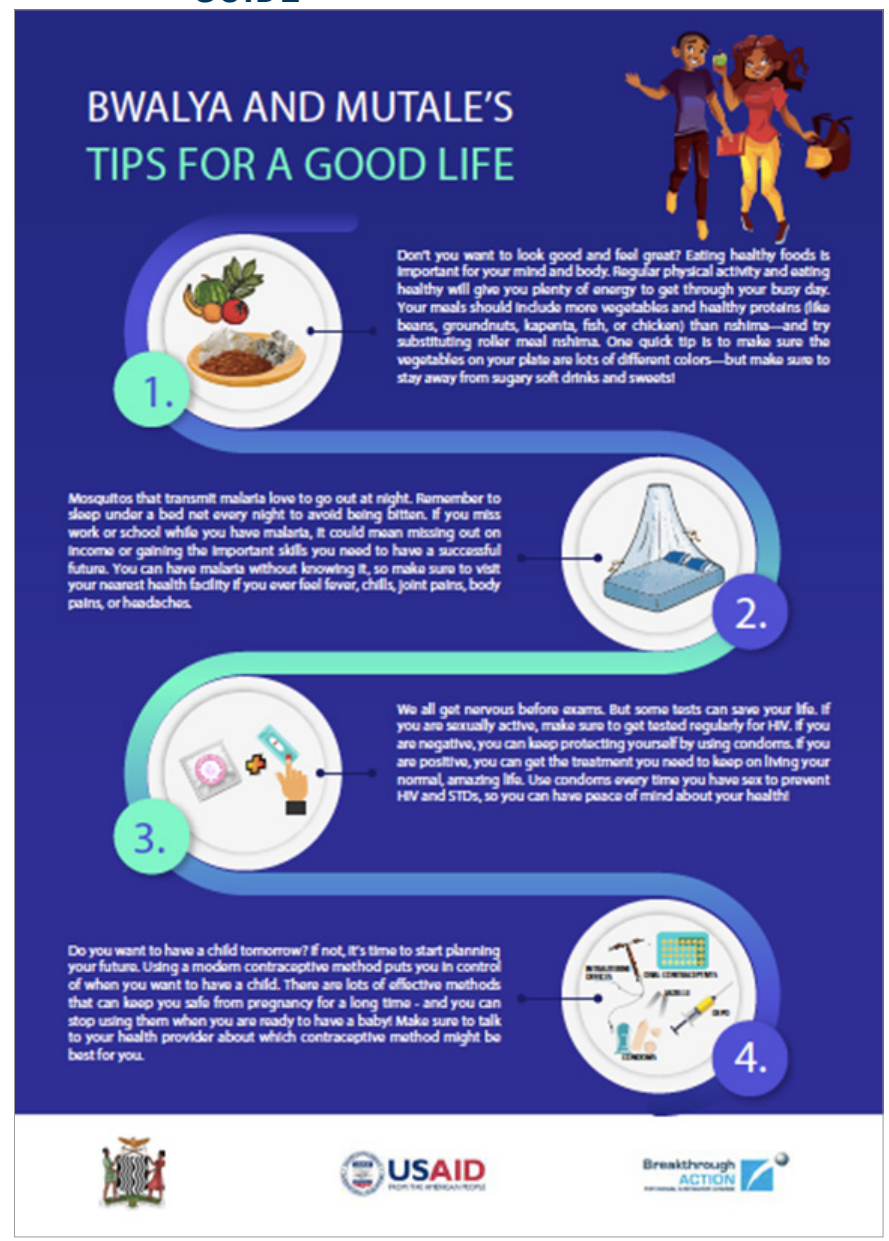

presentations paired with role playing, providing health care providers an overview of the Wellness Day intervention prior to values clarification, key strategies for providing high quality, youth-friendly care, and preparation and strategies for integrated Wellness Days.

Wellness Day trainings recommended an integrated job aid specifying the steps for each consultation. Trainers instructed health providers that clients should be screened for HIV risk using the risk assessment tool, with only clients at risk of HIV being offered an HIV test; likewise, only clients with malaria symptoms would be offered a malaria test. Service providers were advised that following each consultation every client should receive a "Tips for a Good Life" packet (Figure 2) with information on nutrition and fitness, malaria, HIV, and FP to take home, in addition to a supply of condoms.

During the trainings, each district health facility team documented an action plan to determine crucial Wellness Day responsibilities. Original requirements for Wellness Days included a minimum of three trained health providers and two CBVs at each event, with CBVs assisting with client registration and weight and height checks. Additional health workers could be recruited from nearby health facilities, with the assistance of provincial and district health promotion officers. Figure 3 describes key processes taking place at Wellness Days.

\section{FIGURE 3 ELEMENTS OF ADOLESCENT AND MEN'S WELLNESS DAYS}
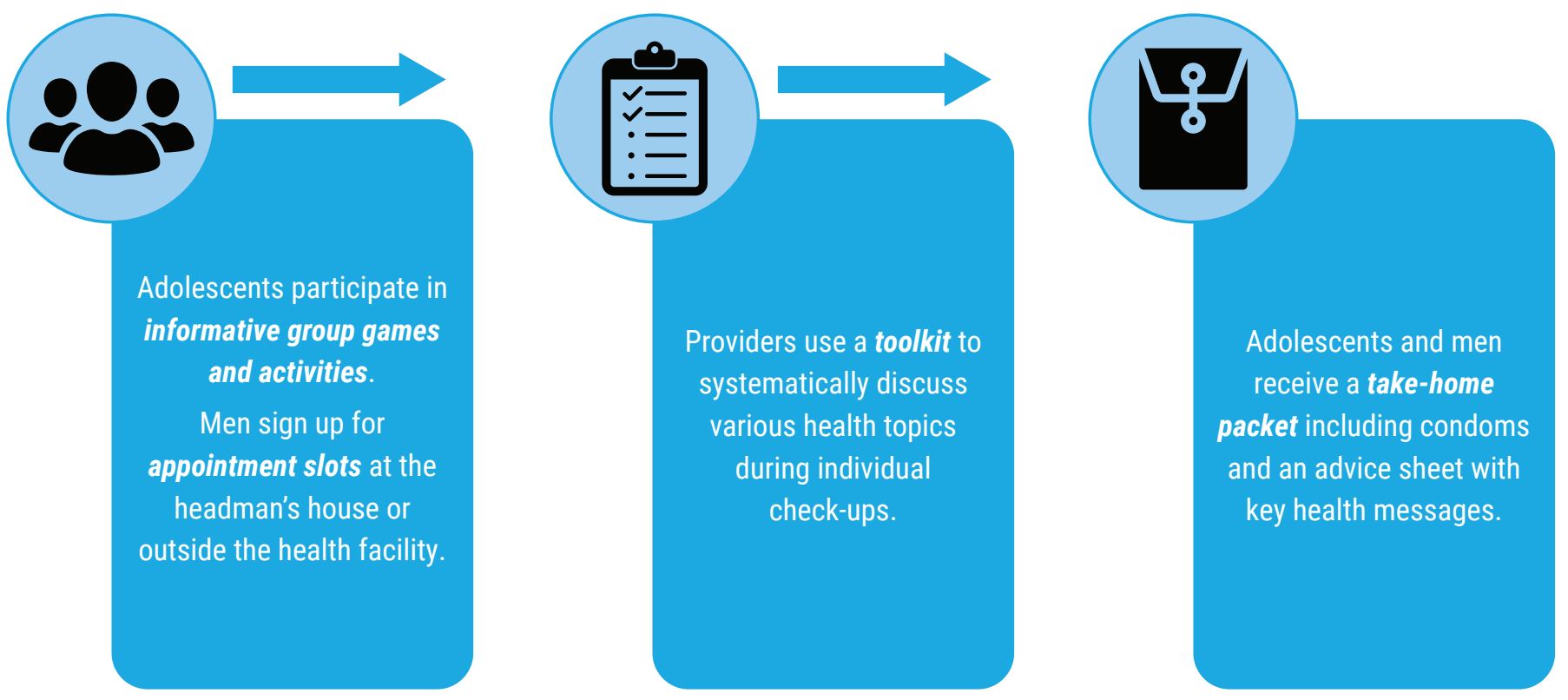


\section{Key Findings}

These findings are derived from surveyed district health care providers' perspectives and experiences during Wellness Days at their facilities.

Providers believe that the process of iterative behavioral insight research, with image elicitation and human-centered design for a refined set of health messages, successfully addressed practical health issues for both men and adolescents.

Health care providers indicated that the health messages in the materials provided to clients, along with condom provision, in addition to the job aids used for counseling, were practical, appropriately targeted, and addressed priority health issues of concern among adolescents and men in their communities.

The [health] messages are appropriate.... The content, is also an actual existing problem in the community.... So the messages are reaching out to actual problems that are existing in the community.... [The IEC materials] are very practical [among youth and men].

-Health Provider, Chembe

\section{Providers stated that integrated SBC} messaging incorporated in Wellness Day counseling and materials led to increased voluntary health services among men and adolescents.

Health care providers mentioned increased frequencies of clients seeking care after integrated SBC counseling during the Wellness Days. Health care providers believe integrated SBC messaging and counseling not only encouraged attendees to come for health services more often, but created an enabling environment that reduced stigma, a health care barrier indicated by the formative research.

At least [during Wellness Days] we are seeing men they are free and they are coming to ask for whatever service they need like for condoms even being tested for HIV, even weighing some can just come through to say I have come to check my blood pressure or my weight just like that. There has been that change especially for men.

-Health Provider, Itezhi Itezhi District

Demand for commodities and services from providers not specifically promoted by Wellness Days also increased.

Health care providers indicated increased demand for additional commodities and services such as male circumcision, cancer screening, and dental care, among others.

Providers recognize that adolescents and adult men are at different life stages and require different kinds of information and styles of integrated SBC counseling.

Some health care providers noted different factors of behavior change among men and youth, male and female, as these two audiences are at different life stages (e.g., physically, cognitively, and socially) and have different risk behaviors. Many health providers interviewed requested additional information and coaching for integrated counseling to support different target populations, especially adolescents.

...A 15 year old boy would come and ask for condoms...we ensure that we practically teach these adolescents on how a condom is used, but you find that after giving the health education what they are more interested in is to carry the condoms and not really learn about how they are supposed to use it.... With them it's the excitement of getting a condom and going to use it; not really knowing how you are supposed to use it.

-Health Provider, Chinsali District 


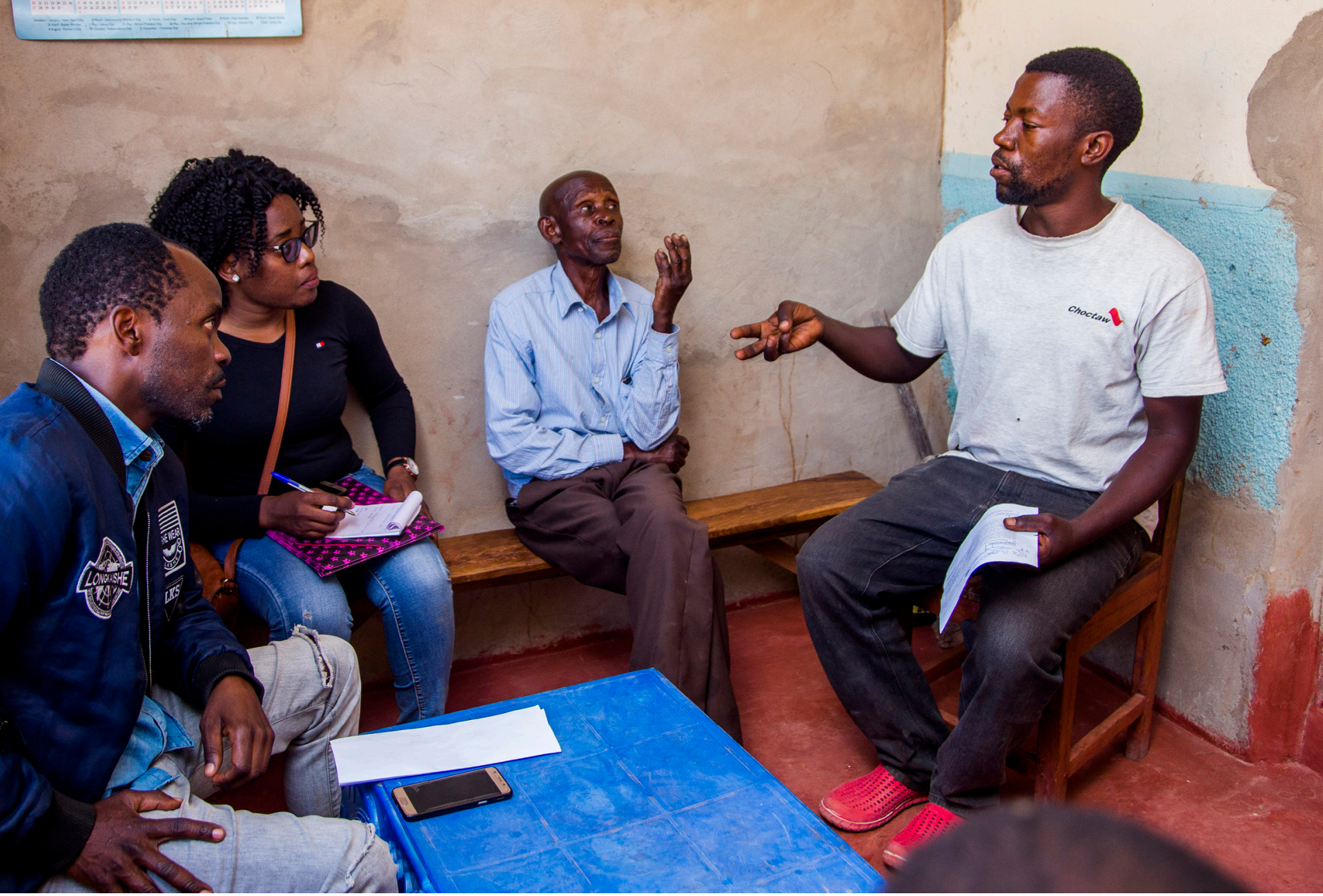

Men's Wellness Day in Chinsali

\section{Recommendations}

\section{Expand use of innovative, formative research} approaches that explore and examine entrenched perceptions and norms that may not be revealed through standard evaluations or surveys.

Behavioral insights and human centered-design approaches are increasingly being used to develop innovative and contextually-relevant interventions because of the involvement of their target audiences in the design process. Participatory approaches, such as focus group discussions, can ensure responses to specific as well as larger challenges informed by those most directly impacted.

\section{Ensure provider training that focuses on the varied and specific needs of men and adolescents.}

Expand the content of existing cascading trainings and dedicate time during refresher trainings to include adolescent-specific and particular health information (e.g., nutrition). Incorporate skills-building (with continued role playing, with response mechanisms), counselor training, discrete life stage trainings, as well as any additional training needed for SBC integration. $\mathrm{MoH}$ can introduce and strengthen these components in their current health care provider training curricula.

\section{Consider additional supply and service availability as a result of increased attendance for integrated services or SBC counseling at a facility.}

There are potential positive, unanticipated outcomes for men and women who attend these services, particularly when "gateway behaviors" such as HIV testing and counseling increase demand for services such as male circumcision. Successful interventions make clients feel more comfortable asking for additional services and commodities not included in specific integrated SBC campaigns. Referral mechanisms should also be strengthened so clients receive not only immediate but comprehensive care. 


\section{Acknowledgments}

This programmatic research brief describes research conducted by Breakthrough RESEARCH in Zambia. This brief and the work it describes is possible through the work and support of Breakthrough ACTION Zambia, Population Council Washington DC and Zambia, and USAID.

\section{Suggested citation:}

Breakthrough RESEARCH. 2020. "Documenting lessons from an integrated social and behavior change program linked to integrated health services in Zambia," Programmatic Research Brief. Washington DC: Population Council.

Photo credits: (B) Breakthrough ACTION Zambia

C 2020 The Population Council. All rights reserved.

\section{Email}

\section{BreakthroughResearch@popcouncil.org}

\section{Breakthrough RESEARCH | Population Council}

4301 Connecticut Ave., NW, Suite 280 | Washington, DC 20008

+12022379400 | breakthroughactionandresearch.org

Breakthrough RESEARCH is made possible by the generous support of the American people through the United States Agency for International Development (USAID) under the terms of cooperative agreement no. AIDOAA-A-17-00018. The contents of this document are the sole responsibility of Breakthrough RESEARCH and Population Council and do not necessarily reflect the views of USAID or the United States Government.

\section{Breakthrough} RESEARCH TOR SOCAL \& BEHAVIOR CHANGE

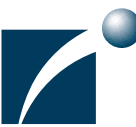

\section{POPULATION} COUNCIL

Ideas. Evidence. Impact.
Our project turns evidence into action by providing thought provoking guidance to improve social and behavior change (SBC) policy and programming, with the goal of improving the cost-effectiveness of USAID's health and development strategies. Breakthrough RESEARCH catalyzes SBC by conducting state-of-the-art research and evaluation and promoting evidence-based solutions to improve health and development programs around the world. Breakthrough RESEARCH is a consortium led by the Population Council in partnership with Avenir Health, ideas42, Institute for Reproductive Health at Georgetown University, Population Reference Bureau, and Tulane University. 